\title{
MicroRNA-182 improves spinal cord injury in mice by modulating apoptosis and the inflammatory response via IKK $\beta / \mathrm{NF}-\mathrm{KB}$
}

\author{
Min $\mathrm{Fei}^{1} \cdot$ Zheng $\mathrm{Li}^{2} \cdot$ Yuanwu $\mathrm{Cao}^{2} \cdot$ Chang Jiang ${ }^{2} \cdot$ Haodong $\operatorname{Lin}^{3} \cdot$ Zixian Chen $\mathbb{( I D}^{2}$ \\ Received: 15 October 2020 / Revised: 31 March 2021 / Accepted: 1 April 2021 / Published online: 31 May 2021 \\ (c) The Author(s), under exclusive licence to United States and Canadian Academy of Pathology 2021. This article is published with open access
}

\begin{abstract}
Spinal cord injury (SCI) is one common neurological condition which involves primary injury and secondary injury. Neuron inflammation and apoptosis after SCI is the most important pathological process of this disease. Here, we tried to explore the influence and mechanism of miRNAs on the neuron inflammatory response and apoptosis after SCI. First, by re-analysis of Gene Expression Omnibus dataset (accession GSE19890), miR-182 was selected for further study because of its suppressive effects on the inflammatory response in the various types of injuries. Functional experiments demonstrated that miR-182 overexpression promoted functional recovery, reduced histopathological changes, and alleviated spinal cord edema in mice. It was also observed that miR-182 overexpression reduced apoptosis and attenuated the inflammatory response in spinal cord tissue, as evidenced by the reduction of tumor necrosis factor (TNF)- $\alpha$, interleukin (IL)-6, and IL-1 $\beta$, and the induction of IL10. Using a lipopolysaccharide (LPS)-induced SCI model in BV-2 cells, we found that miR-182 was downregulated in the BV-2 cells following LPS stimulation, and upregulation of miR-182 improved LPS-induced cell damage, as reflected by the

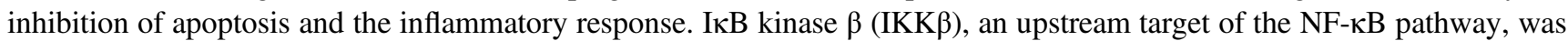
directly targeted by miR-182 and miR-182 suppressed its translation. Further experiments revealed that overexpression of IKK $\beta$ reversed the anti-apoptosis and anti-inflammatory effects of miR-182 in LPS stimulated BV-2 cells. Finally, we found that miR-182 overexpression blocked the activation of the NF- $\mathrm{kB}$ signaling pathway in vitro and in vivo, as demonstrated by the downregulation of phosphorylated (p-) IкB- $\alpha$ and nuclear p-p65. Taken together, these data indicate that miR-182 improved SCI-induced secondary injury through inhibiting apoptosis and the inflammatory response by blocking the IKK $\beta /$ NF- $\mathrm{kB}$ pathway. Our findings suggest that upregulation of miR-182 may be a novel therapeutic target for SCI.
\end{abstract}

These authors contributed equally: Min Fei, Zheng Li

Haodong Lin

haodonglin@hotmail.com

Zixian Chen

chen.zixian@zs-hospital.sh.cn

1 Department of Anesthesiology, Zhongshan Hospital, Fudan University, Shanghai, China

2 Department of Orthopedics, Zhongshan Hospital, Fudan University, Shanghai, China

3 Department of Orthopedic Surgery, Shanghai General Hospital, Shanghai Jiaotong University School of Medicine, Shanghai, China

\section{Introduction}

Spinal cord injury (SCI) is a common neurological condition with high mortality and disability worldwide [1]. Although great improvement in treatment methods for SCI has been made, such as drug therapy, surgical treatment, and transplantation therapy, no SCI treatment can achieve a complete cure [2]. A number of studies have revealed that secondary damage is critical in the pathological progression of SCI, with marked effects on neuron apoptosis and the inflammatory response, which can lead to severe neurological damage and dysfunction [3-5]. However, few studies have been conducted on the mechanisms of secondary injury after SCI.

The inflammatory response is a major event in secondary injury in SCI, which is regulated by various pathways including the NF- $\kappa \mathrm{B}$, MAPKs, and IL-6R/JAK-STAT pathways, though the NF- $\mathrm{kB}$ pathway has been the most thoroughly studied [6-8]. The degradation of IKB mediates 
activation of NF- $\mathrm{KB}$ signaling pathway, and the IкB kinase (IKK) complex can promote the phosphorylation of IкB [9]. In the IKK complex, the catalytic subunit IKK $\beta$ has an important role in the phosphorylation of the IKB protein [10]. In spinal cord tissue, NF- $\mathrm{KB}$ is usually activated in nerve cells and microglia after SCI. Once activated, the secretions of a large number of inflammatory cytokines such as IL-1, TNF- $\alpha$, IL- 6 , aggravated secondary damage after SCI $[11,12]$. Therefore, suppression of the NF- $\mathrm{kB}$ pathway limits pro-inflammatory phenotypes and improves the secondary injury.

MicroRNAs (miRNAs) are single-stranded non-coding RNAs that bind to the target mRNAs and interfere their translation [13, 14]. Recent evidence indicates that miRNAs are abnormally expressed in plasma of SCI patients, which suggests that miRNAs can function as novel biomarkers for disease diagnostics $[15,16]$. As well as global miRNA changes, the roles of specialized miRNAs in SCI have been elucidated through the use of animal models [17, 18]. For example, Wang et al. showed that miR-940 was decreased in the spinal cords of mice with SCI, and overexpression of miR-940 promoted the recovery of SCI by inhibiting inflammation [19]. Xu et al. showed that miR-124 improved functional recovery through suppressing neuronal cell apoptosis in SCI rats [20]. However, limited studies have been published on the role of miRNAs in the pathophysiology of secondary damage after SCI.

In the present study, through the re-analysis of the Gene Expression Omnibus (GEO) dataset (accession GSE19890), miR-182 was identified as one of the downregulated miRNAs with the smallest change in a mouse model of contusive SCI. Subsequently, the function of miR-182 was further elucidated using agomir-miR-182 injection in this model. Moreover, the underlying mechanisms of the miR182-mediated protective role in SCI were investigated in vitro and in vivo. Our findings may increase our understanding of miR-182 regulation after SCI and promote the development of therapeutic measures for SCI.

\section{Materials and methods}

\section{Animals and grouping}

Female C57BL/6 mice (12 weeks, 18-24 g) were purchased from SLAC Laboratory Animal Co., Ltd (Shanghai, China) and housed under standard conditions ( $12 \mathrm{~h}$ light-dark cycle, $25-27^{\circ} \mathrm{C}, \sim 40 \%$ humidity) with free access to food and water throughout the duration of the experiments. All experimental procedures were approved by the Animal Ethics Committee of Zhongshan Hospital, Fudan University. The animals were randomly divided into four groups: Sham $(n=36), \mathrm{SCI}(n=36), \mathrm{SCI}+$ agomir-miR-182 $(n=36)$, and
$\mathrm{SCI}+$ agomir-negative control (NC) $(n=36)$. All groups were subdivided into six time points: 1-, 3-, 7-, 14-, 21- and 28-day post-SCI ( $n=6$ per time point). All animals survived the experimental period without adverse effects and were included in the data analysis.

\section{SCI model establishment}

Mice were anesthetized with pentobarbital sodium $(50 \mathrm{mg} /$ $\mathrm{kg}$ ) by intraperitoneal injection, and a laminectomy was performed at thoracic vertebra level $\mathrm{T} 10$ as previously described [21], and the spinal cord was exposed. SCI was induced by the weight drop $(10 \mathrm{~g})$ from a $2.5-\mathrm{cm}$ height on a T10 spinal cord. Sham-injured animals were only subjected to a laminectomy without hitting the T10 spinal cord. Animal procedures were approved by the Institutional Animal Care and Use Committee of Zhongshan Hospital, Fudan University.

\section{Injection of agomir-miR-182}

Mice were randomly divided into four groups to determine the role of agomir-miR-182: SCI group, Sham group, SCI + agomir-miR-182 group, and SCI + agomir-NC group. In the SCI + agomir-miR-182 group/agomir-NC group $(n=6 /$ group/time), the mice were subjected to SCI and then the mixed miR-182 agomir $(20 \mu \mathrm{M}, 2 \mu \mathrm{L})$ was injected into the mice using a glass micropipette (tipdiameter $20-40 \mu \mathrm{m}$ ) via intrathecal injection. The injection rate was $0.2 \mu \mathrm{L} / \mathrm{min}$, and the needle was left in place for an additional $5 \mathrm{~min}$ before being slowly withdrawn. The dose of the agomir-miR-182 was based on the results obtained from in spared nerve injury (SNI) model [22]. After 4 weeks, all mice were sacrificed following pentobarbital $(50 \mathrm{mg} / \mathrm{kg}$, i.p) anesthetization, and subsequently, a $10 \mathrm{~mm}$ long segment of the spinal cord centered at the injury epicenter was harvested for further experiments. The miR-182 agomir (5'UUUGGCAAUGGUAGAACYCACACCG-3 ${ }^{\prime}$ ) and its scrambled negative control (5'-UUCUCCGAACGUGU CACGUTT-3') were synthesized by GenePharma (Shanghai, China).

\section{Basso, Beattie, and Bresnahan (BBB) score}

BBB score was performed to test locomotor function of mice at $1,3,7,14,21$, and 28 days post injury in an open field, and was scored between 0 (no observable hind-limb movements) and 21 (normal locomotion) as described previously [23]. At each time point, the outcome value for each mouse was obtained by averaging motor score from the observation and scoring of behaviors involving the hindlimbs. The scores were recorded by two well-trained investigators who were blind to the experiments. 


\section{$\mathrm{HE}$ and Cresyl violet staining}

A $10 \mathrm{~mm}$ long segment of the spinal cord containing the epicenter from indicated groups were fixed with $4 \%$ paraformaldehyde (Solarbio, China), embedded in paraffin, and cut into $10-\mu \mathrm{m}$ thick serial sections. One set of tissue sections were used for routine HE staining (Beyotime, China). The others were put onto Superfrost Plus Slides and every 40th section was stained with $0.5 \%$ cresyl-violet acetate and imaged using BX51 light microscope (Olympus Inc., Tokyo, Japan). Using Image-Pro Plus 6.0 (Media Cybernetics, USA) software, the lesion area and spared tissue area were outlined and quantified as described previously [24].

\section{Spinal cord water content measurement}

The spinal cord tissues obtained in the above experimental procedure at 7 days post injury were immediately weighted, and then the dry weight of spinal cord tissues was obtain at $100{ }^{\circ} \mathrm{C}$ for $24 \mathrm{~h}$. The ratio of wet-to-dry weight calculated as follows: [(wet weight - dry weight)/wet weight] $\times 100 \%$.

\section{TUNEL staining}

Apoptosis in spinal cord tissues was detected by Situ Cell Death Detection Kit (cat no.11684817910, Roche). The $10 \mathrm{~mm}$ spinal cord sections were deparaffinized and rehydrated in an alcohol gradient. After washing with PBS, TUNEL reaction mixture preparation and staining were performed according to the manufacturer's protocol. The images were captured by the inverted fluorescence microscope ( $\times 400$ magnification, Olympus Inc., Tokyo, Japan). The TUNEL-positive cells in 10 random fields of each section were counted for analysis.

\section{Immunohistochemical (IHC) and immunofluorescent analysis (IFA)}

IHC and IFA staining was performed as previously described [25], with specific antibody for caspase-3 (cat no. 9662), p-IкB $\alpha$ (Ser32 cat. no. 2859), and nuclear p-p65 (cat. no. 3033). All antibodies were obtained from Cell Signaling Technology, Inc., Danvers, MA, USA. Images of IHC were photographed using an Olympus BX51 light microscope (Olympus Inc., Tokyo, Japan) and the images of IFA were captured by fluorescence microscopy (Olympus Inc., Tokyo, Japan) at $\times 200$ magnification. Positively stained cells of IHC were observed and counted by the Image-Pro Plus image analysis management system (Media Cybernetics, Rockville, MD). Five random fields from each slide were selected for capture and counting of positive cells.

\section{ELISA assay}

Spinal cord tissue was dissected and placed in pre-cooled PBS buffer, and then homogenized with a homogenizer. The supernatant was collected by centrifugation at $3000 \mathrm{r} / \mathrm{min}$ for $20 \mathrm{~min}$ at $4{ }^{\circ} \mathrm{C}$. For cultured cells, the supernatant was collected after treatment, and the supernatant was carefully collected by centrifugation at $2000 \mathrm{r} /$ min for 20 min. IFN- $\alpha$ (cat no.BMS6027), IL-1 $\beta$ (cat no. BMS6002), IL-6 (cat no. BMS603-2), and IL-10 (cat no. 88-7105-22) were measured by ELISA kit (all from Thermo Fisher Scientific, Inc., Waltham, MA, USA) according to manufactures.

\section{miRNA microarray}

Microarray dataset GSE19890 was obtained from the National Center for Biotechnology Information (NCBI) GEO database (http://www.ncbi.nlm.nih.gov/geo) to identify SCI associated miRNAs. GSE19890 dataset was based on miRCURY LNA microRNA Array, v.11.0 platform. GEO2R (www.ncbi.nlm.nih.gov/geo/geo2r/), an interactive web tool was applied to compare the samples in two different groups under the same experimental condition. $\log _{2}$ (Fold Change)l $\left(\log _{2}(\mathrm{FC}) \mid\right)$ was selected as the criteria to screen the statistically significant differentially expressedmiRNAs (DE-miRNAs) [26]. The procedure and imaging processes were as described previously [27].

\section{RNA isolation and quantitative RT-PCR}

Total RNA was extracted from spinal cord and cells with a miRNeasy Mini kit (Qiagen GmbH, Hilden, Germany). Reverse transcription of miR-182 was synthesized using the miScript II RT kit (Invitrogen, Carlsbad, CA). miR-182 expression was measured using the Exiqon SYBR Green Master Mix (Exiqon, Vedbaek, Denmark) on an ABI Prism 7900 HT (Applied Biosystems). The primers used for were as follows: miR-182 RT primer 5'-GTCGTATCCAGTGCAGG GTCCGAGGTATTCGCACTGGATACGACAGCCTACGG TGT-3'; forward: 5'-CGTCCTTTGGCAATGGTAGAACTC3', reverse: 5'-GCAGGGTCCGAGGTATTC-3'; U6 forward: 5'-GCTTCGGCAGCACATATACTAAAAT-3', reverse: 5'-C GCTTCAGAATTTGCGTGTCAT- ${ }^{\prime}$. The relative expression of each gene was calculated using the $2^{-\Delta \Delta \mathrm{Ct}}$ method [28].

\section{Cell culture and treatment}

BV-2 cells were widely used to induce cell injuries to mimic the in vitro model of SCI [29]. The BV-2 cell line was obtained from ATCC (Manassas, VA, USA) and maintained in DMEM/F12 (Gibco; Thermo Fisher Scientific, Inc., Waltham, MA, USA) containing 10\% FBS 
(Gibco), and $1 \%$ penicillin and streptomycin (SigmaAldrich, St. Louis, MO, USA) in $5 \% \mathrm{CO}_{2}$ at $37^{\circ} \mathrm{C}$.

For the induction of inflammation and apoptosis in the cultured BV-2 cells, $100 \mathrm{ng} / \mathrm{ml}$ of lipopolysaccharide (LPS) were used to stimulate cells (Sigma-Aldrich, St Lousis, MO, USA) for $4 \mathrm{~h}$ at $37^{\circ} \mathrm{C}$ as previously reported [30].

\section{Cell transfection}

When BV-2 cells grown to about $80 \%$ confluence in six-well plate, $20 \mathrm{nM}$ agomiR-182 or $2 \mu \mathrm{g}$ pcDNA-IKK $\beta$ were transfected into cells at $37^{\circ} \mathrm{C}$ for $48 \mathrm{~h}$, using Lipofectamine 2000 (Invitrogen). The agomir-miR-182 and agomiR-negative control (NC), were obtained from RiBoBio (Guangzhou, China). IKK $\beta$ overexpressing vector pcDNA-IKK $\beta$ and pcDNA vector were constructed by Qiagen (USA).

\section{Caspase-3 activity and NF-KB activity assay}

After treatment, total protein was extracted using RIPA buffer (cat no.P0013B, Beyotime Institute of Biotechnology) and protein concentration was evaluated using the bicinchoninic acid assay (cat no.P0010S, Beyotime Institute of Biotechnology), according to the manufacturer's protocols. Then, the activity of caspase-3 was evaluated using a caspase-3 activity kit (cat no.C1115, Beyotime Institute of Biotechnology) according to the manufacturer's protocols.

The NF- $\mathrm{B}$ activity was assessed as previously described [31]. Briefly, BV-2 cells were plated in six-well plates at a concentration of $5 \times 10^{4}$ cells/well for $24 \mathrm{~h}$, and then transfected with $2.5 \mu \mathrm{g}$ of a NF- $\kappa \mathrm{B}$ reporter luciferase construct. After $6 \mathrm{~h}$, the cells were washed and then cotransfected with agomiR-182 and pcDNA-IKK $\beta$ for $24 \mathrm{~h}$. The cells were then washed in PBS and harvested in $500 \mu \mathrm{l}$ $1 \times$ passive lysis buffer. Promega luciferase assay kit was performed to quantify the Luciferase activity using a on a luminometer.

\section{Luciferase reporter assay}

pGL3-IKK $\beta$ wide type (Wt) or pGL3-IKK $\beta$ mutant type (mut) plasmids were co-transfected with $20 \mathrm{nM}$ agromiR182 into BV-2 cells in 24 -well plates $\left(2 \times 10^{5} /\right.$ well $)$ using Lipofectamine 2000 (Invitrogen). At $24 \mathrm{~h}$ post-transfection, the double luciferase activities were analyzed using the Dual-Luciferase Reporter Assay system (Promega Corporation) and normalized to Renilla luciferase activity.

\section{Western blot analysis}

Western blot was performed as previously described [29]. Briefly, $40 \mu \mathrm{g}$ extracted protein samples from spinal cord and cells were transferred onto a PVDF (Millipore) membrane and then this membrane was blocked with $5 \%$ skim milk for $2 \mathrm{~h}$ at room temperature, followed by incubation with primary antibodies against cleaved-caspase-3 (cat. no. 9664), p-IкB $\alpha$ (Ser32 cat. no. 2859), IKK $\beta$ (cat. no. 9188), $\mathrm{I} \kappa \mathrm{B} \alpha$ (cat. no. 4812), nuclear p-p65 (cat. no. 3033), p65 (cat. no. 8242), IL-6 (cat. no. \#12912), IL-10 (cat. no. 12163), IL-1 $\beta$ (cat. no. 12703), TNF- $\alpha$ (cat. no. 11948), Bax (cat. no. 14796), Bcl-2 (cat. no. 4223), cleaved PARP (cat. no. 5625) and $\beta$-actin (cat. no. \#4970) at $4{ }^{\circ} \mathrm{C}$ overnight. All antibodies were obtained from Cell Signaling Technology, Inc and the dilution was 1:1000. Subsequently, the blots were incubated with appropriate secondary antibodies (cat. no. 7074; Cell Signaling Technology, Inc. 1:2000) for $1 \mathrm{~h}$ at room temperature. The protein bands were developed using ECL kit (GE Healthcare) and blot bands were quantified with ImageJ version 1.46 (Rawak Software, Inc. Munich, Germany).

\section{Statistical analysis}

Statistical analysis was performed using GraphPad Prism (version 5.0, Inc., La Jolla, CA, USA). Data were recorded as means $\pm \mathrm{SD}$. Differences among multiple groups were analyzed by one-way analysis of variance with Tukey's post hoc test, and differences between two groups were analyzed by Student's $t$ test. A $p$ value $<0.05$ was considered significant. Each experiment was repeated at least three times.

\section{Results}

\section{miR-182 was downregulated in spinal cords of SCI mice}

We established an experimental model of SCI mice injury in vivo as previously described [32], and then evaluated the behavioral analyses using $\mathrm{BBB}$ motor rating scale. As shown in Fig. 1A, mice from sham group showed no locomotor impairment and maintained full marks in the BBB score for 28 days. Immediately after SCI, mice in SCI group showed paralysis of both hindlimbs. Although motor functions gradually improved until the end of the experiment, much lower BBB scores were observed in SCI group compared with the Sham group. Cresyl violet staining showed that mice in SCI group showed a significant decrease in the amount of spared tissue in the rostral and caudal directions from the injury epicenter (Fig. 1B). It was also observed that the water contents in spinal tissue samples were time-dependently increased in SCI group compared with Sham group (Fig. 1C). In addition, compared with the sham group, a greater number of TUNEL-positive cells were observed in the SCI group, as determined by 
A

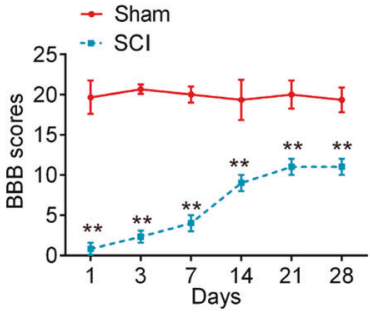

D
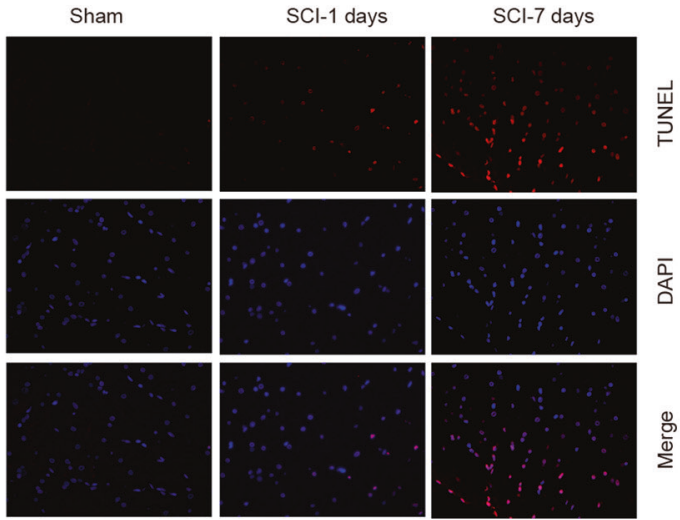

B

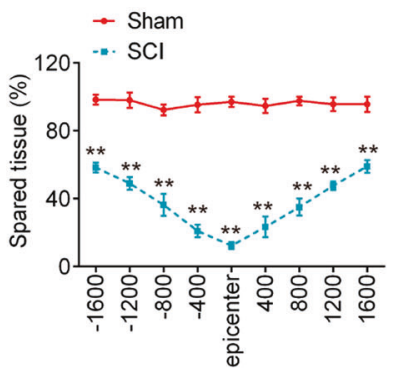

G

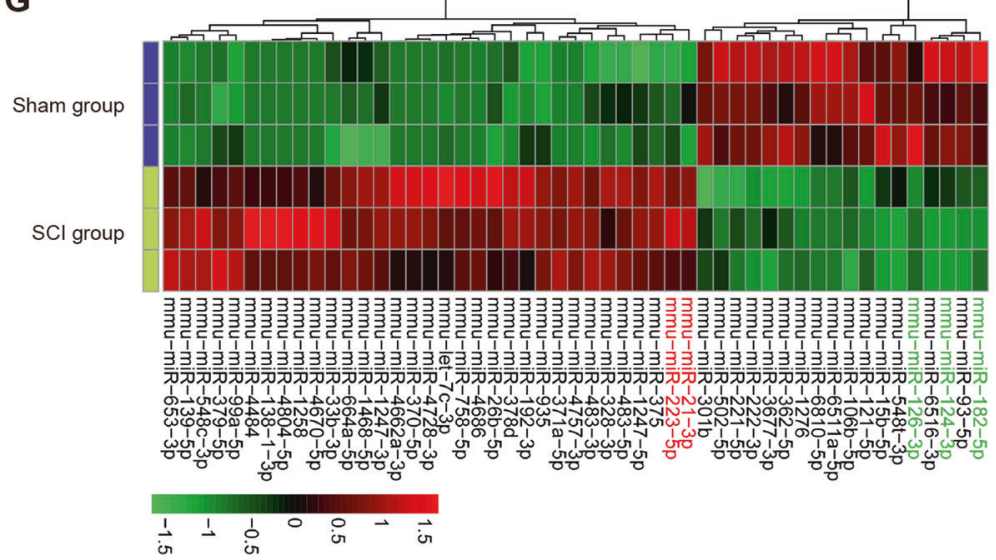

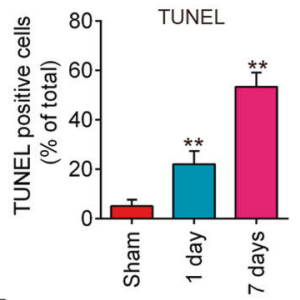

$\mathbf{F}$

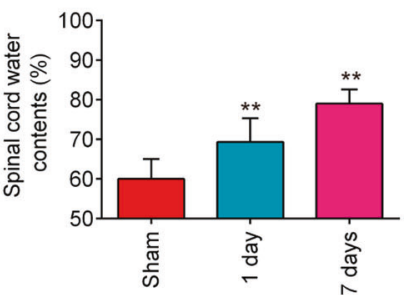

E

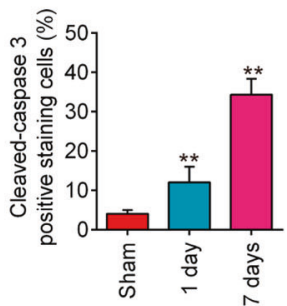

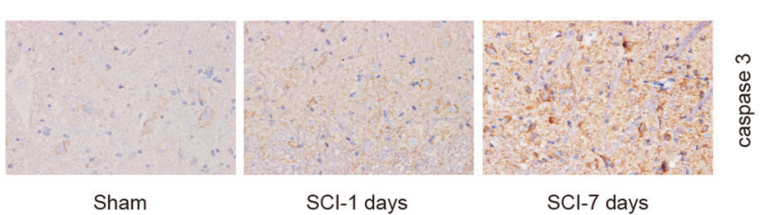

$\mathrm{H}$

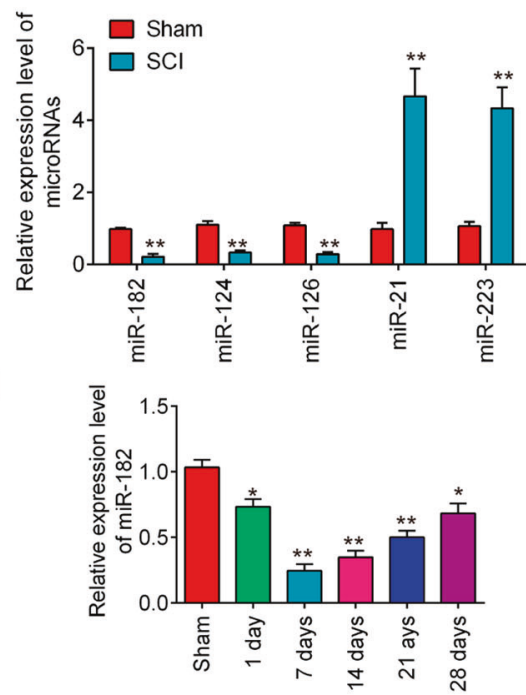

Fig. 1 miR-182 was downregulated in the spinal cords of SCI mice. A The BBB scores at 1, 3, 7, 14, 21, and 28 days after SCI were shown for all groups of mice ( $n=6$ /group). B Quantification of spared tissue within the injury site, and $1600 \mu \mathrm{m}$ rostral and caudal to the epicenter, 28 days post injury ( $n=6$ /group). C Spinal cord water content was assessed using wet-to-dry weight method ( $n=6 /$ group). D Apoptosis was determined by TUNEL staining at 1 and 7 days post injury $(n=6 /$ group). E, F The expression of casapse-3 was measured by IHC at 1

TUNEL staining assay (Fig. 1D). Concomitantly, the expression of caspase- 3 in spinal tissues, an established indicator of apoptosis [33], were significantly increased at 1 $\mathrm{d}$ and $7 \mathrm{~d}$ post injury (Fig. 1E, F), as determined by IHC. All data indicted SCI model was successfully constructed, and $\mathrm{SCI}$ can induce neuronal apoptosis.

and 7 days after SCI ( $\times 200$ magnification) $(n=6 /$ group $)$. G A cluster heap map was used to present the upregulated and downregulated miRNAs from GSE19890. H qRT-PCR was performed to detect the expression of miR-182, miR-124, miR-126, miR-21, and miR-223 ( $n=6$ /group). I qRT-PCR was performed to determine the expression levels of miR-182 in spinal cord tissues from mice at 1, 7, 14, 21, and 28 days after SCI ( $n=6 /$ group/time). Data represent the mean \pm SD of three independent experiments. ${ }^{*} p<0.05,{ }^{* *} p<0.01$ vs. Sham group.

In order to identify miRNAs associated with SCI, microarray dataset GSE19890 was retrieved from GEO database. Various miRNAs showed differential expression in the microarray analysis, including 33 upregulated miRNAs and 18 downregulated miRNAs compared with Sham group (Fig. 1G). To further verify these differential expression of 
miRNAs, the 5 miRNAs ( 3 most significantly upregulated or 2 downregulated miRNAs) were selected and quantified by qRT-PCR analysis. It was shown that miR-182, miR-21, and miR-223 were significantly increased, while miR-124 and miR-126 were markedly decreased in the spinal cord tissues (Fig. 1H), which are consistent with previous reports $[20,24,34,35]$, indicating the reliability of this microarray. But, in the present study, miR-182 exhibited the most downregulated changes in spinal tissues of SCI mice, and the anti-inflammatory effects of miR-182 have been identified in several types of cells [36-40]. Additionally, two previous studies have reported that miR-182 improved the neurological function of rats in SNI and SCI models [22, 41]. However, whether miR-182 can exert protective effects against the inflammatory response and apoptosis in the secondary injury of SCI remains unclear. Therefore, we focused on miR-182 for further investigation.

Next, the expression change of miR-182 was calculated in spinal cord tissues of mice at different time points. As shown in Fig. 1I, the miR-182 expression levels were reduced at different time points after SCI compared to the expression in the sham group. The decrease in level of expression of miR-182 was minimal at 7 days post injury and then its expression was gradually increased persisted until 28 days after injury. All data indicates that miR-182 may be involved in the pathogenesis of SCI.

\section{Agomir-miR-182 improved functional recovery and suppressed neuron apoptosis}

To further examine the impact of miR-182 in behavioral motor functions after SCI, agomir-miR-182 and agomiR$\mathrm{NC}$ were intrathecally injected into SCI mice. The agomirmiR-182 transfection efficiency was assessed by qRT-PCR. As shown in Fig. 2A, miR-182 was significantly increased in spinal cord tissues of SCI mice from 1 to $28 \mathrm{~d}$ post injury, compared with agomiR-NC group. Histopathologic changes were assessed using HE staining. As shown in Fig. 2B, the sham group displayed a well-defined border between gray matter and white matter, and neurons were abundant. In the injury group, tissue sections contained numerous red blood cells along the injury site with abundant inflammatory cells, particularly glial cells proliferation and satellitosis (microglial cells surrounding neurons with swollen and prenecrotic neurons). Moreover, the injury group had a disordered spinal cord structure including indiscriminate structures between gray matter and white matter, the number of neurons was lowered considerably. However, treatment with agomir-miR-182 attenuated injury remarkably. The structure of the spinal cord was better and the number of neurons greater than that in the injury group (Fig. 2B) The BBB score was performed to evaluate hindlimb motor function recovery of SCI mice following agomir-miR-182 injection.
As shown in Fig. 2C, agomir-miR-182 injection significantly improved $\mathrm{BBB}$ scores for up to 4 weeks compared with the SCI plus agomir-NC group. Meanwhile, we found that the amount of spared tissue was markedly increased in SCI + agomir-miR-182 group compared with the SCI plus agomir-NC group, indicating that agomir-miR182 can reduce lesion size in SCI mice (Fig. 2D). In addition, the spinal cord wet-to-dry ratio was evaluated to indicate the spinal cord water edema and we found that agomir-miR-182 treatment dramatically decreased the spinal cord water edema, compared with the SCI plus agomir-NC group (Fig. 2E). Furthermore, the effect of miR182 on apoptosis in the SCI mice was analyzed by TUNEL staining. It was found that agomir-miR-182 injection resulted in a marked reduction of TUNEL-positive cells, compared with the SCI plus agomir-NC group (Fig. 2F, G). Finally, the expression of caspase- 3 in spinal cord tissues was notably suppressed by agomir-miR-182, as determined by immunohistochemistry (IHC) staining (Fig. 2H). Taken together, miR-182 upregulation could promote functional recovery and protect neurons apoptosis in SCI mice.

\section{Agomir-miR-182 injection inhibited the inflammatory response in $\mathrm{SCl}$ mice}

To further evaluate the influence of antagomiR-182 on the inflammatory response, the releases of TNF- $\alpha$, IL- 6 , IL-1 $\beta$, and IL-10 in serums of SCI mice were measured by ELISA. As shown in Fig. 3A-D, compared with the sham group, the expression levels of TNF- $\alpha$, IL- 6 , IL- $1 \beta$ were significantly increased, but IL-10 was markedly decreased in SCI mice. However, agomir-miR-182 treatment reduced the expression of these pro-inflammatory cytokines, while enhanced the levels of IL-10 induced by SCI. The suppressive effects of agomir-miR-182 on SCI-induced inflammatory response were also confirmed by western blot analysis in spinal tissues (Fig. 3E). These data suggest that agomir-miR-182 suppressed the SCI-induced inflammatory response in mice.

\section{Overexpression of miR-182 suppressed the inflammatory response and apoptosis in an $\mathrm{SCl}$ cell culture model}

As already known, LPS-induced BV-2 cell injury model has been widely used to mimic the pathological characteristics of SCI in vitro [42]. To further explore the functions of miR-182 in LPS-induced BV-2 cell injury, the agomir-miR182 was added to BV-2 cells $4 \mathrm{~h}$ prior to LPS treatment. qRT-PCR assay showed that miR-182 was significantly increased after agomir-miR-182 transfection in BV-2 cells (Fig. 4A). Following treatment of the BV-2 cells with various concentrations of LPS $(10-1000 \mathrm{ng} / \mathrm{ml}), \mathrm{miR}-182$ was downregulated in LPS-treated BV-2 cell, and this effect 
A

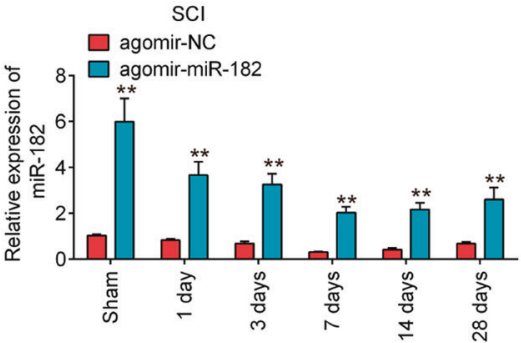

C

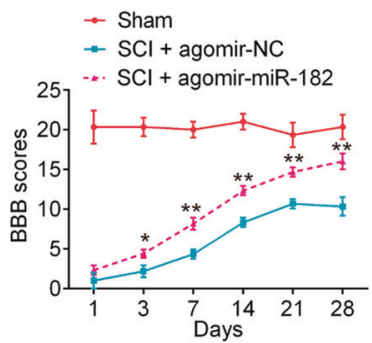

D

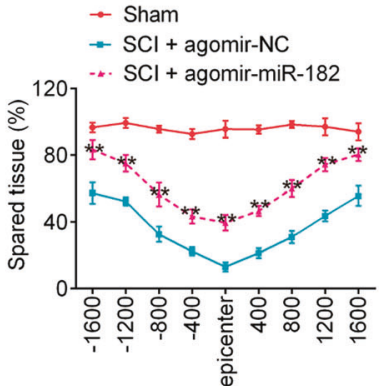

G
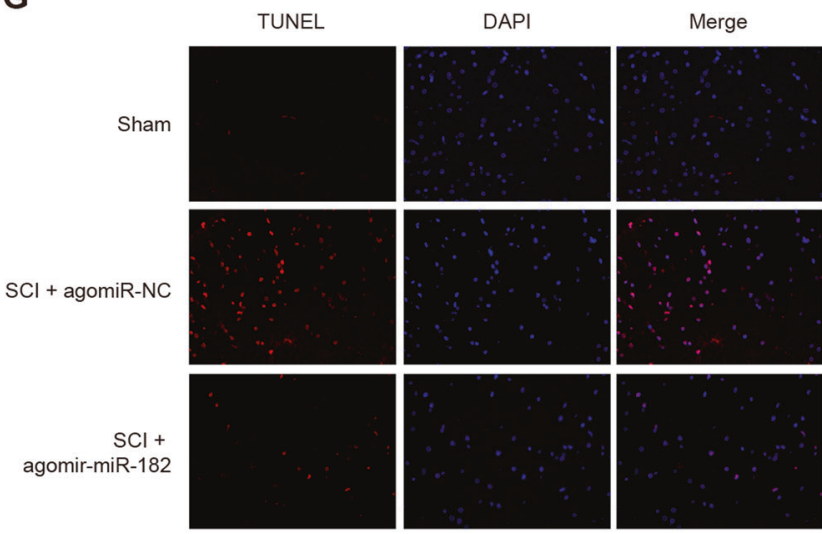

B

E
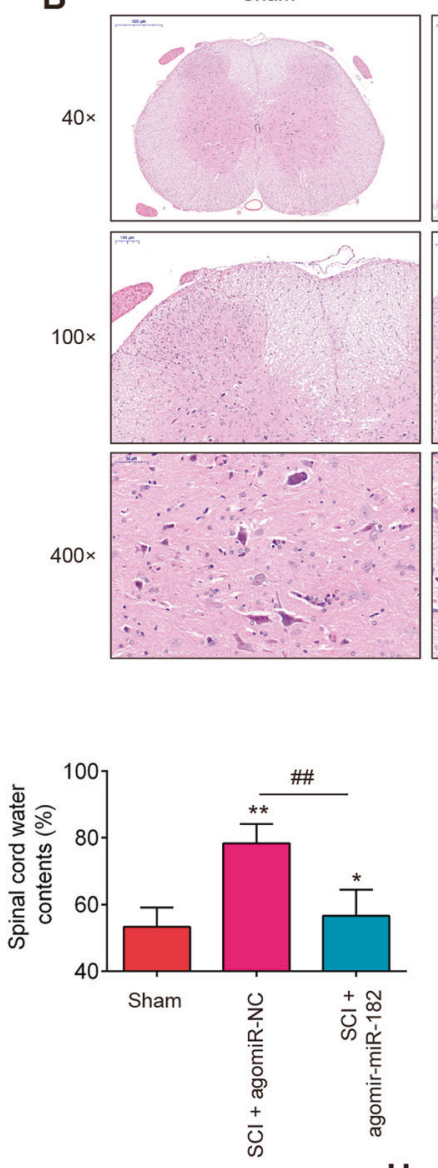

$\mathrm{H}$

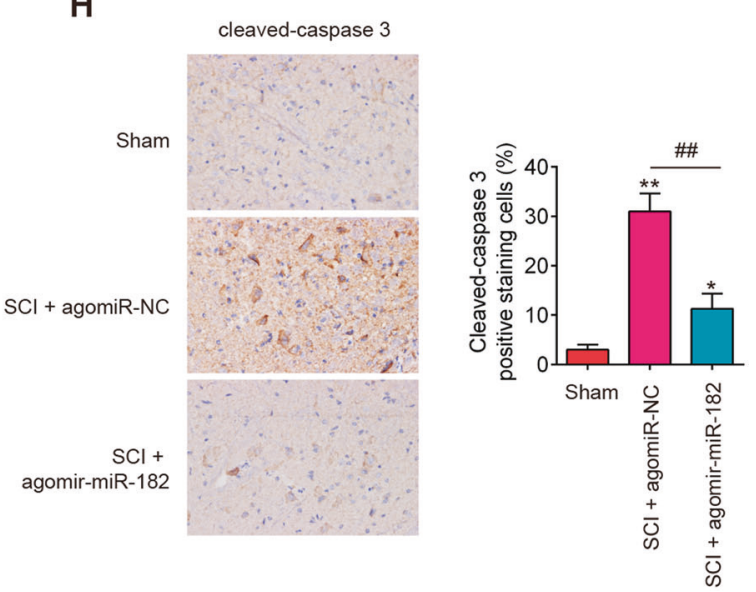

Fig. 2 Agomir-miR-182 improves recovery of SCI mice by reducing apoptosis. The mice were subjected to SCI and treated intrathecally with agomir-miR-182/agomir-NC $(2 \mu \mathrm{l}, 20 \mu \mathrm{M})$. At indicated time, the animals were sacrificed following pentobarbital sodium $(50 \mathrm{mg} / \mathrm{kg}$, i.p) anesthesia, and subsequently, a $10 \mathrm{~mm}$ long segment of the spinal cord was harvested for further experiments. A qRT-PCR was performed to determine the expression levels of miR-182 in spinal cord tissues at $1,3,7,14,21$, and 28 days after agomir-182 injection ( $n=6 /$ group/time). B The staining images of spinal cord tissues following Hematoxylin and eosin (HE) staining ( $n=6 /$ group). The red blood cells is indicated with red arrow. The inflammatory cell infiltration is indicated with green arrow. The glial cells proliferation and satellitosis (microglial cells surrounding neurons with swollen and prenecrotic neurons) is indicated with black arrow. C The BBB scores at $1,3,7,14,21$, and 28 days after SCI were shown for all groups of rats $(n=6 /$ group/time). D Quantification of spared tissue within the injury site, and $1600 \mu \mathrm{m}$ rostral and caudal to the epicenter, 7 days post injury ( $n=6$ /group). E Spinal cord water content was assessed using wet-to-dry weight method ( $n=6 /$ group). F, G TUNEL staining of neuronal apoptosis at 1 and 7 days post injury ( $n=6 /$ group/time). $\mathbf{H}$ The expression of casapse- 3 was detected by IHC at 1 and 7 days post injury ( $n=6 /$ group/time). Data represent the mean $\pm \mathrm{SD}$ of three independent experiments. ${ }^{*} p<0.05,{ }^{*} p p<0.01$ vs. Sham group; ${ }^{\# \#} p<$ 0.01 vs. SCI + agomir-NC group. 
A

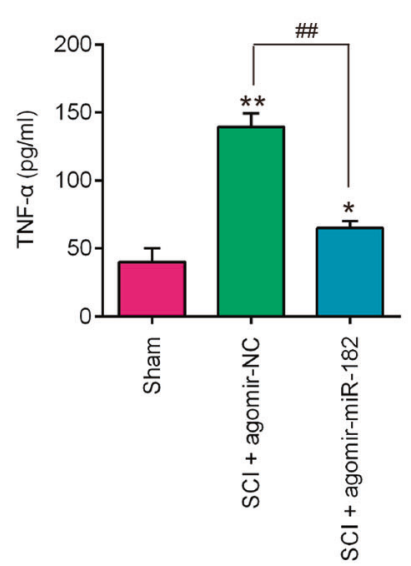

D

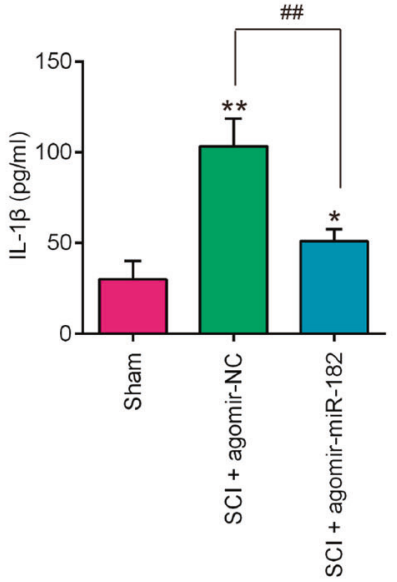

Fig. 3 miR-182 inhibited the inflammatory response in SCI mice. The mice were subjected to SCI and treated intrathecally with agomirmiR-182/agomir-NC $(2 \mu \mathrm{l}, 20 \mu \mathrm{M})$. At 7 days post injury, the animals were sacrificed following pentobarbital $(0.3 \mathrm{~g} / \mathrm{kg}$, i.p) anesthesia, and subsequently, the spinal cord tissues were harvested for further experiments. A-D ELISA analysis of TNF- $\alpha$, IL-6, IL-10, and IL-1 $\beta$ in

was dose-dependent (Fig. 4B). Thus, $100 \mathrm{ng} / \mathrm{ml}$ LPS was selected as the appropriate concentration in the subsequent experiments, which is consistent with a previous study [43]. Then, we evaluated whether miR-182 affects apoptosis in this SCI cell culture model. The data showed that compared with control group, the activity of caspase 3 in LPS plus agomir-NC group was concomitantly upregulated, and the increase was significantly reduced in the presence of agomir-miR-182 (Fig. 4C). The expression of caspase-3, determined as using IFA assay, was found to be increased in response to LPS stimulation, whereas agomir-miR-182 treatment significantly inhibited the LPS-induced caspase-3 expression (Fig. 4D). In addition, the expression of Bcl-2 in LPS plus agomir-NC group was significantly decreased, and the expression of Bax, cleaved caspase- 3 and cleavedPARP were obviously increased, compared with control group. As expected, these effects of LPS on apoptotic related protein expression were attenuated after agomirmiR-182 treatment, suggesting that miR-182 upregulation suppressed LPS-induced apoptosis in BV-2 cells (Fig. 4E).
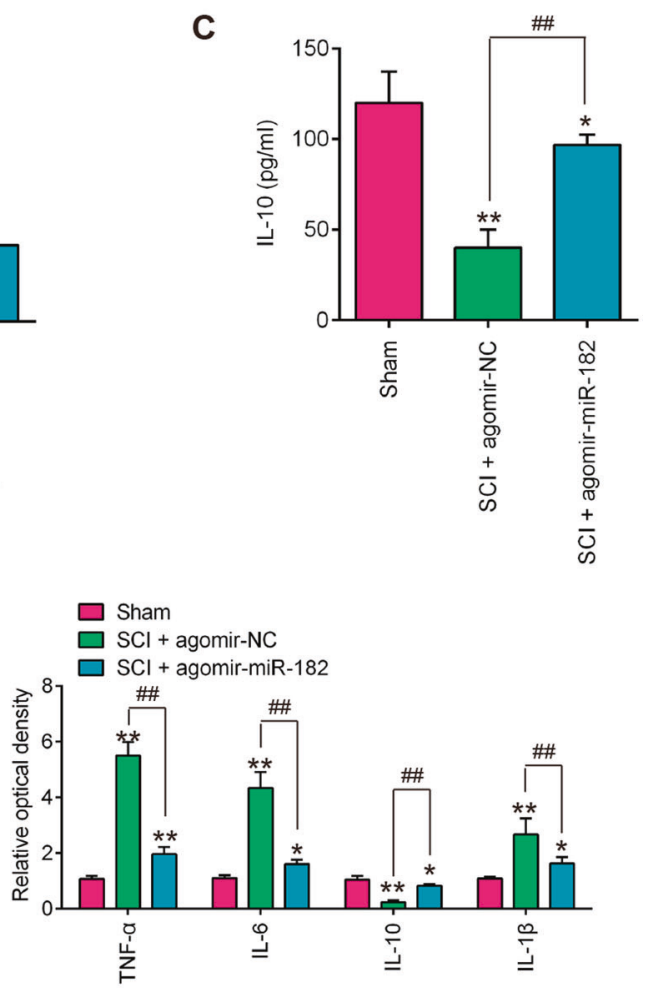

serum of SCI rat after agomir-miR-182 injection ( $n=6$ /group). E Western blot analysis of TNF- $\alpha$, IL-6, IL-10, and IL-1 $\beta$ in spinal cord tissues ( $n=6$ /group). Data represent the mean $\pm \mathrm{SD}$ of three independent experiments. * $p<0.05,{ }^{*} p<<0.01$ vs. Sham group; ${ }^{\# \#} p<$ 0.01 vs. SCI + agomir-NC group.

The impact of miR-182 overexpression on the secretions of inflammatory cytokines was further assayed. As shown in Fig. 4F-I, agomir-miR-182 treatment markedly inhibited the expression levels of pro-inflammatory cytokines (TNF- $\alpha$, IL-6, IL-1 $\beta$ ), but promoted the expression of IL-10 in LPS plus agomir-miR-182, compared with LPS plus agomir-NC group. The data suggest that miR-182 upregulation protected the BV-2 cells from LPS-induced apoptosis and the inflammatory response.

\section{IKK $\beta$ is a functional target of miR-182 in BV-2 cells}

To explore the underlying molecular mechanisms involved in the miR-182-mediated protective in LPS-induced apoptosis and inflammatory responses, we relied on TargetScan 7.0 and miRanda to predict the targets of miR-182 and identified IKK $\beta$ as a potential target of miR-182 (Fig. 5A). Next, a luciferase reporter assay was performed in BV-2 cells to determine whether IKK $\beta$ is a direct target of miR182. As shown in Fig. 5B, agomir-miR-182 significantly 

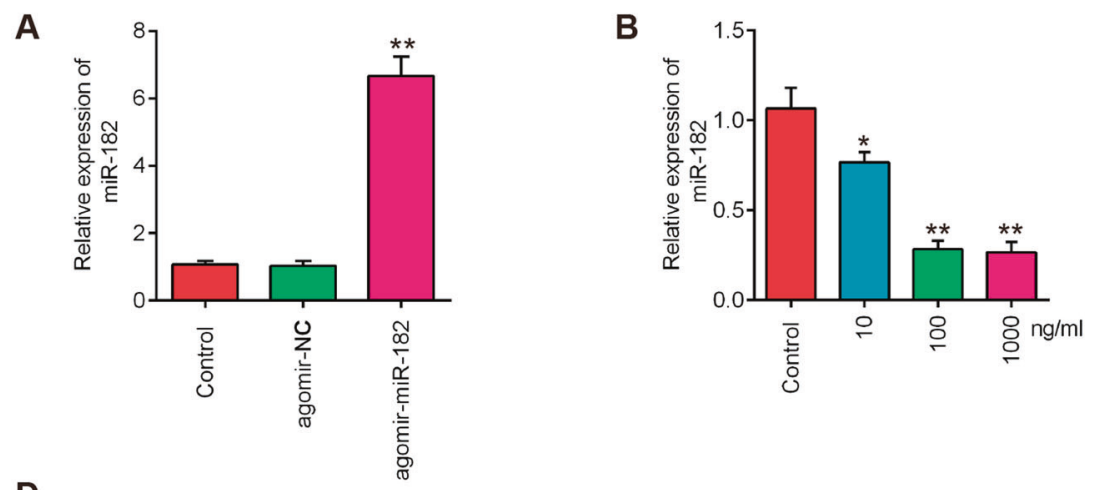

D
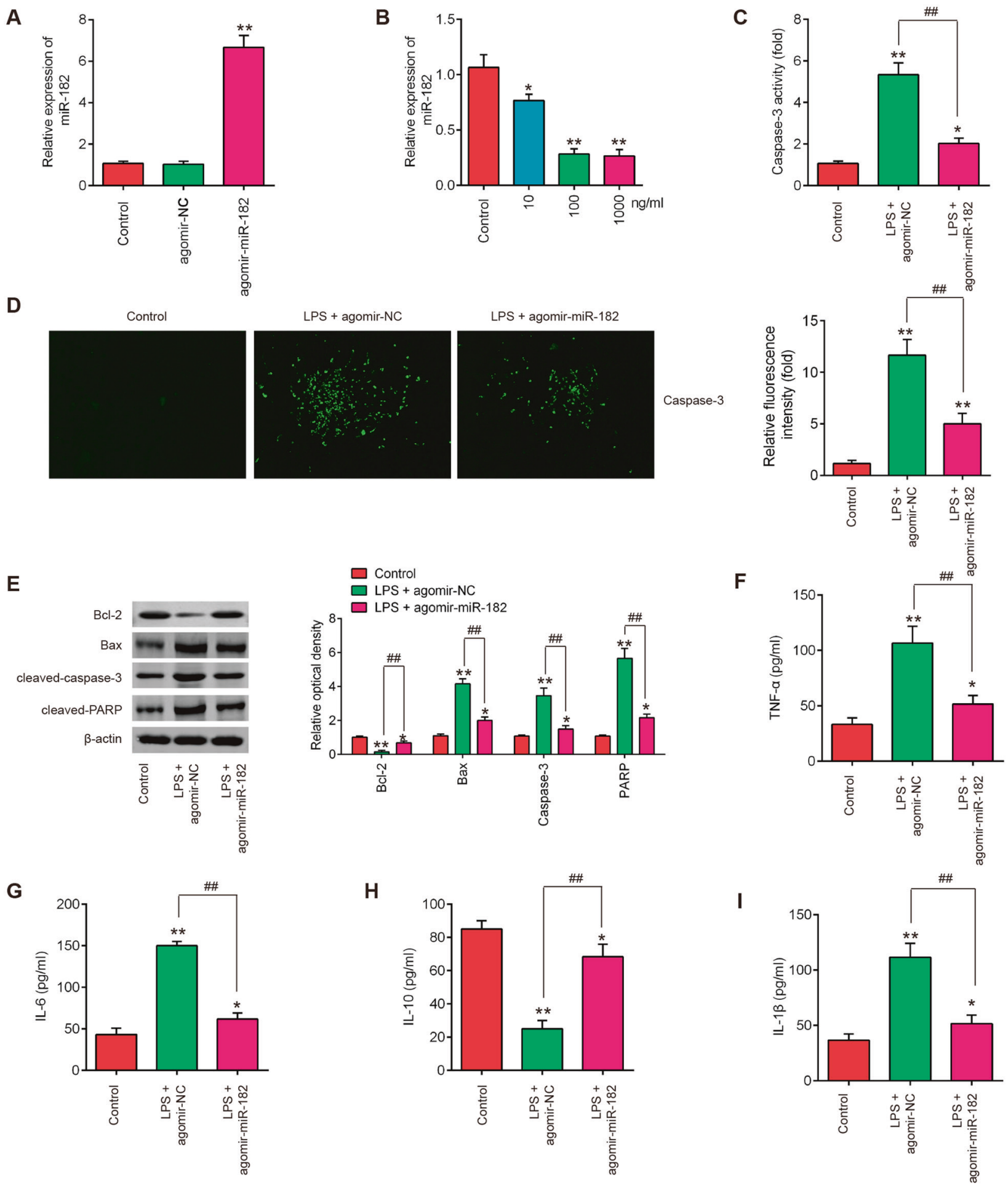

Fig. 4 Overexpression of miR-182 suppressed the inflammatory response and apoptosis in an SCI cell culture model. A AgomirmiR-182 was added to the cultured BV-2 cells $\left(1 \times 10^{6} /\right.$ well $)$ and incubated for $24 \mathrm{~h}$, and then the transfected efficiency of miR-182 was detected by qRT-PCR analysis. B BV-2 cells $\left(1 \times 10^{6} /\right.$ well $)$ were treated with different concentrations of LPS $(10,100$, and $1000 \mathrm{ng} / \mathrm{ml})$ for $24 \mathrm{~h}$, and the expression of miR-182 was detected by qRT-PCR analysis. Agomir-miR-182 was added to the cultured BV-2 cells $(1 \times$ $10^{6} /$ well) $4 \mathrm{~h}$ prior to LPS treatment and incubated for $24 \mathrm{~h}$, and then

cells were harvested for subsequent experiments. C Activity of caspase-3 was measured using a commercial kit. D The protein expression level of caspase-3 was detected by IFA. E The protein expression levels of Bcl-2, Bax, cleaved-caspase-3, and cleaved-PARP were detected by western blot analysis. F-I The expression of TNF- $\alpha$, IL-6, IL-10, and IL-1 $\beta$ were measured by ELISA analysis. Data represent the mean $\pm \mathrm{SD}$ of three independent experiments. ${ }^{*} p<0.05$, ${ }^{* *} p<0.01$ vs. Control group; ${ }^{\# \#} p<0.01$ vs. LPS + agomir-NC group. 
A

Mouse IKK $\beta$ ENST00000522147.1 3' UTR length: 970

Position 223-229 of IKK 3 3' UTR

wt IKK 3 3'-UTR: 5'...CUGUAGUGAUGGCGAUGCCAAAC... 3' | |||||

mmu-miR-182-5p: 3' ...GCCACACUCAAGAUGGUAACGGUUU... 5'

mut IKKß 3'-UTR:5' ...CUGUAGUGAUGGCGA CAGACGUC... 3'
B

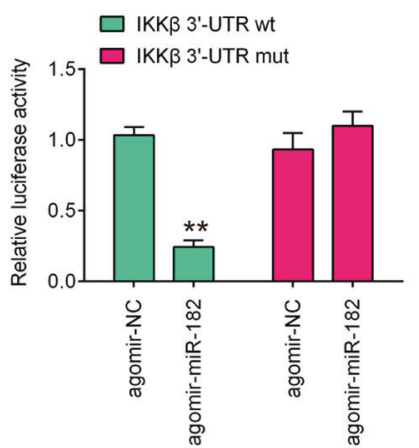

C

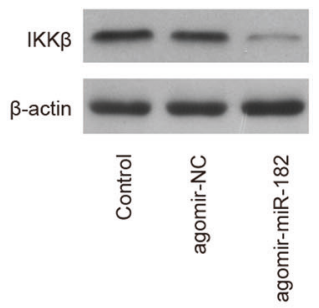

D

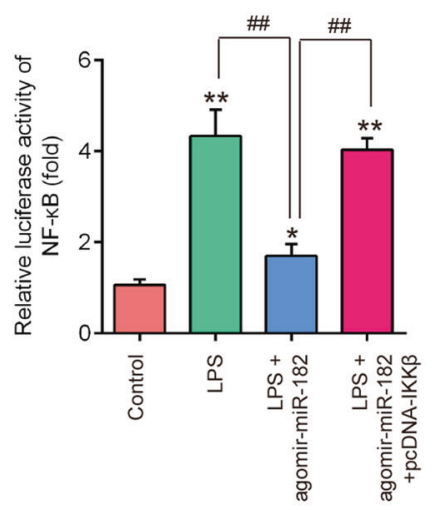

$\mathbf{E}$

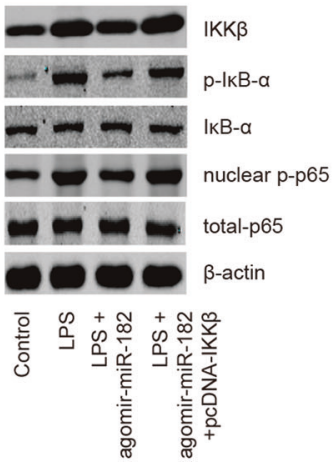

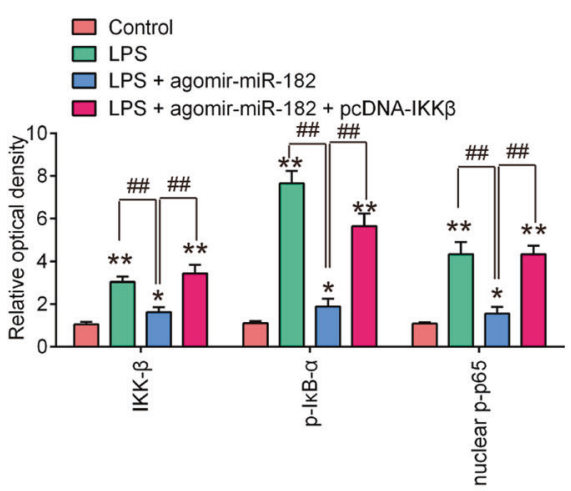

Fig. 5 IKK $\beta$ is a direct target of miR-182 in BV-2 cells. A The predicted miR-182 binding sites on IKK $\beta$. B Luciferase assay of BV-2 cells $\left(1 \times 10^{6} /\right.$ well $)$ co-transfected with firefly luciferase constructs containing the IKK $\beta$ wild-type or mutated $3^{\prime}$-UTRs and agomir-miR182 or agomir-NC, as indicated $(n=3)$. Data represent the mean \pm SD of three independent experiments. ${ }^{* *} p<0.01$ vs. agomir-NC group. C The protein levels of IKK $\beta$ were detected by western blot after agomir-miR-182 transfection. Agomir-miR-182 and pcDNA-IKK $\beta$

repressed the luciferase activity of the IKK $\beta-3^{\prime} \mathrm{UTR}$ wt reporter plasmid. However, there is no change of luciferase activity in the cells co-transfected with aromir-miR-182 and the IKK $\beta-3^{\prime}$ UTR mut reporter plasmid. Furthermore, miR182 overexpression decreased protein level of IKK $\beta$ in BV2 cells, as determined by western blot analysis (Fig. 5C), suggesting that miR-182 suppressed the translation of IKK $\beta$ in BV-2 cells.

Since IKK $\beta$ is a significant activator of the NF- $\mathrm{KB}$ pathway, which is closely associated with the inflammatory response in SCI [19, 44]. To examine whether miR-182 influences the activation of the NF- $\mathrm{KB}$ signaling pathway, we examined the activation of the NF- $\mathrm{KB}$ signaling pathway in LPS-treated BV-2 cells by using a reporter assay. Luciferase activity was significantly increased in LPS group, compared to control group. However, when agomir-miR182 was transfected into LPS-treated cells, there was a significant decrease in luciferase activity in this cell culture model. Importantly, the decreased luciferase activity caused by agomir-miR-182 was reversed by overexpression of IKK $\beta$ in the cell culture model (Fig. 5D). Besides, western blot results showed that LPS treatment led to a significant were co-transfected into the cultured BV-2 cells $4 \mathrm{~h}$ prior to LPS treatment and incubated for $24 \mathrm{~h}$. D The NF- $\mathrm{KB}$ signaling pathway activity in BV-2 cells was measured by a Promega luciferase assay kit. $\mathbf{E}$ The protein expression levels of IKK $\beta$, p-I $\mathrm{I} B \alpha$, I $\kappa \mathrm{B} \alpha$, nuclear-p-p65 and total p65 were detected by western blot analysis. Data represent the mean \pm SD of three independent experiments. $* p<0.05, * * p<0.01$ vs. Control group; ${ }^{\# \#} p<0.01$ vs. LPS + agomir-NC group.

increase in the protein expression of NF- $\kappa \mathrm{B}$ pathway-related proteins, IKK $\beta, \mathrm{p}$-IKB $\alpha$ and nuclear-p-p65, compared to the control group, indicating that LPS activated the NF- $\mathrm{KB}$ pathway in BV-2 cells. In contrast, agomir-miR-182 transfection attenuated the promoting effect of LPS on these proteins. However, the downregulated protein levels of $\mathrm{p}$ IKB $\alpha$, nuclear-p-p65 and IKK $\beta$ induced by miR-182 were reversed when IKK $\beta$ was overexpressed (Fig. 5E). All these results indicated that the effect of miR-182 on the NF- $\mathrm{KB}$ pathway activation is dependent on the targeting of IKK $\beta$.

\section{miR-182 protects BV-2 cells from LPS-induced apoptosis and the inflammatory response by targeting IKK $\beta$}

IKK $\beta$ was a target of miR-182 in BV-2 cells, therefore, we sought to test whether IKK $\beta$ mediated the protection of miR-182 on LPS-induced apoptosis and inflammatory responses. The IKK $\beta$ expression vector, pcDNA-IKK $\beta$ and agomir-miR-182 were co-transfected into BV-2 cells $4 \mathrm{~h}$ prior to LPS treatment. As shown in Fig. 6A, the protein 
A

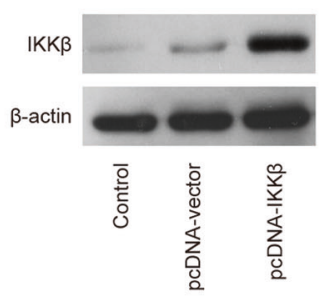

B

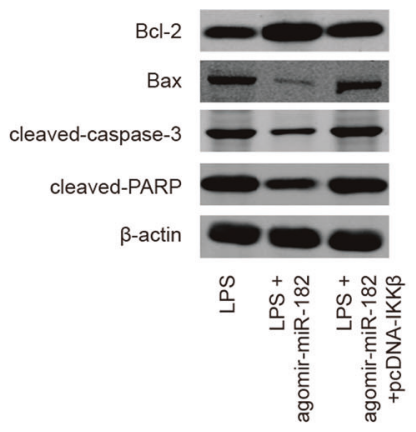

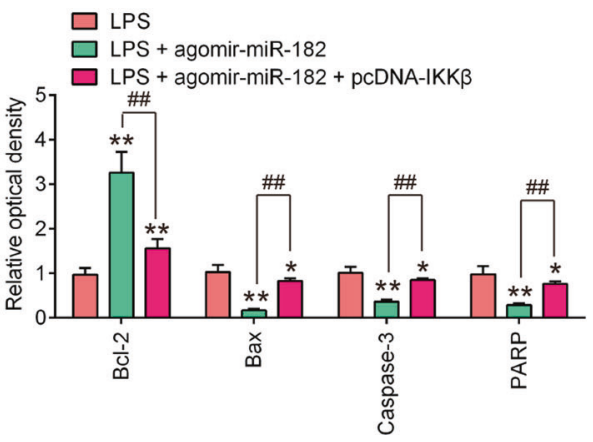

C
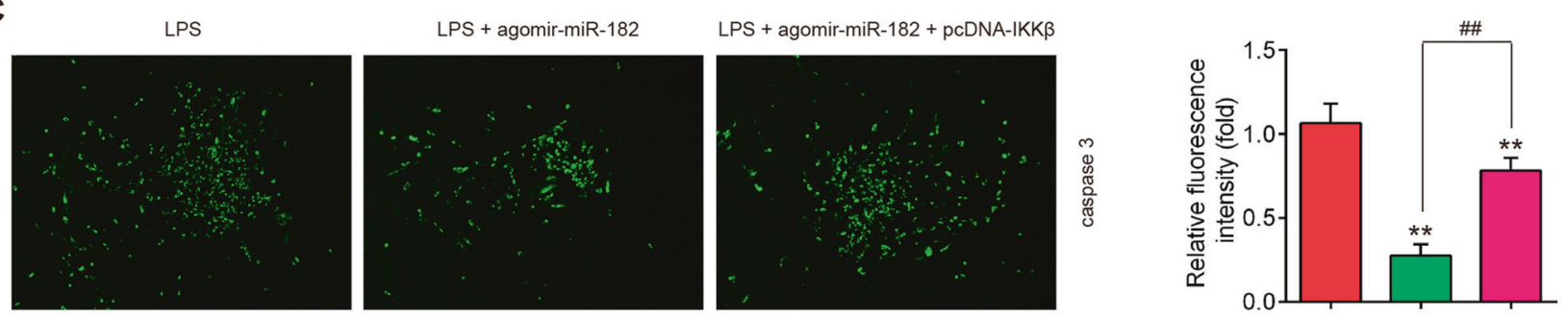

D

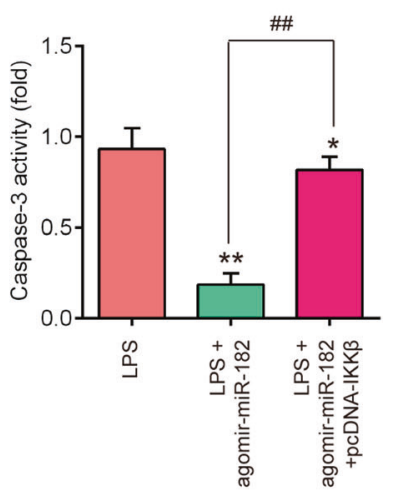

E

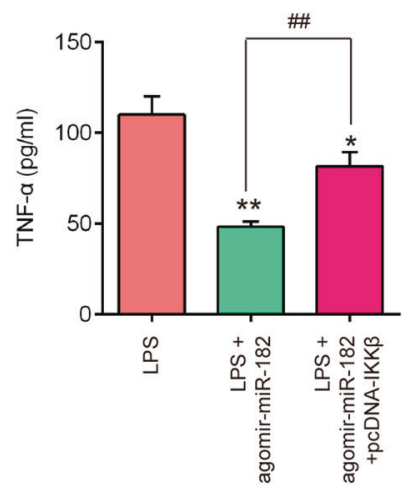

$\mathbf{F}$

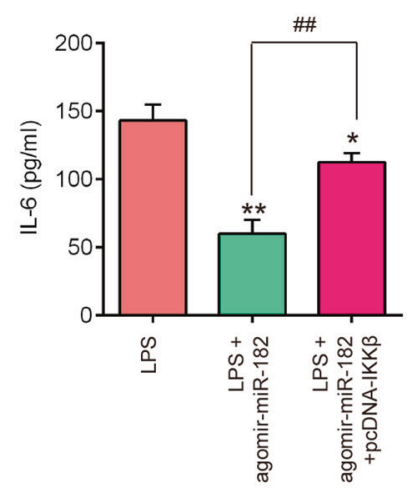

G

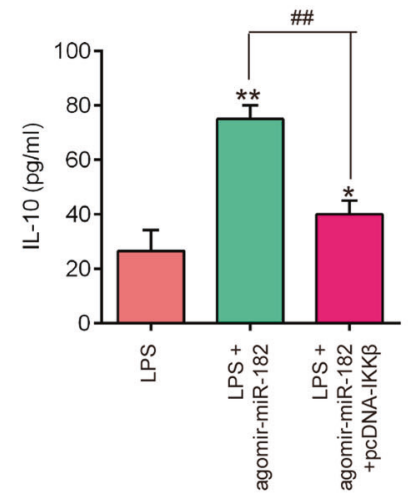

Fig. 6 miR-182 protects BV-2 cells from LPS-induced apoptosis and the inflammatory response by targeting IKK $\beta$. Agomir-miR182 and pcDNA-KK $\beta$ were co-transfected into the cultured BV- 2 cells $\left(1 \times 10^{6} /\right.$ well $) 4 \mathrm{~h}$ prior to LPS treatment, and incubated for $24 \mathrm{~h}$, then cells were harvested for next experiments. A The transfected efficiency of of IKK $\beta$ was determined by western blot. $\mathbf{B}$ The protein expression levels of Bcl-2, Bax, cleaved-caspase- 3 and cleaved-PARP were

expression of IKK $\beta$ was notably increased after pcDNAIKK $\beta$ transfection in BV-2 cells. Functionally, compared with LPS group, agomir-miR-182 decreased Bax, cleaved

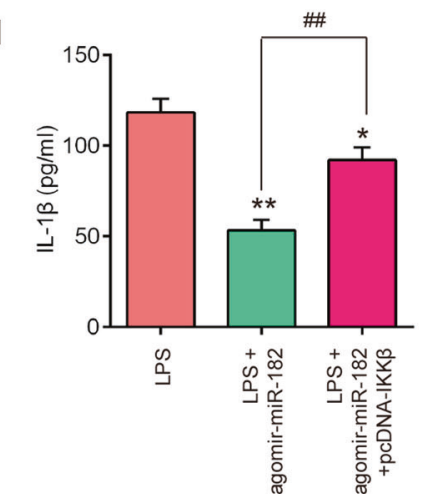

detected by western blot analysis. C The protein expression level of caspase-3 was detected by IFA. D, Activity of caspase-3 was measured using a commercial kit. E-H, The expression of TNF- $\alpha$, IL-6, IL-10, and IL-1 $\beta$ were measured by ELISA analysis. Data represent the mean \pm SD of three independent experiments. ${ }^{*} p<0.05$, ${ }^{*} p<<0.01$ vs. Control group; ${ }^{\# \#} p<0.01$ vs. LPS + agomir-miR-182 group.

caspase-3 and cleaved-PARP protein expression level and increased the $\mathrm{Bcl}-2$ expression, and the effects were reversed by overexpression of IKK $\beta$ in BV-2 cells 
(Fig. 6B). IFA results showed that agomir-miR-182 suppressed LPS-induced caspase-3 expression, and the effect was also reversed by overexpression of IKK $\beta$ (Fig. 6C). Similar results were observed in the activity of caspase- 3 (Fig. 6D). Besides, ELISA was performed to evaluate inflammatory cytokine productions in LPS-treated BV-2 cells following pcDNA-IKK $\beta$ and agomir-miR-182 cotransfection. As shown in Fig. 6E-H, agomir-miR-182 treatment resulted in the reduction of TNF- $\alpha$, IL- 6 and IL$1 \beta$ productions and the induction of the IL-10 production in LPS-treated BV-2 cells, whereas the anti-inflammatory effects of miR-182 were reversed by overexpression of IKK $\beta$. These data suggest that miR-182 protects BV-2 cells from LPS-induced apoptosis and inflammatory responses by targeting IKK $\beta$.

\section{Agomir-miR-182 blocked activation of the NF-kB pathway in vivo}

To test whether miR-182 influences the NF- $\kappa \mathrm{B}$ pathway activation in vivo, western blot was performed to analyze the expression levels of $\mathrm{NF}-\kappa \mathrm{B}$ pathway-related core factors in mice following SCI. As shown in Fig. 7A, B, the expression levels of IKK $\beta$, p-IкB- $\alpha$ and nuclear p-p65 were markedly upregulated in SCI mice compared with sham group, indicating that LPS activates the NF- $\kappa \mathrm{B}$ pathway. However, the activation of the NF- $\mathrm{B}$ pathway was blocked when agomir-miR-182 was treated, as evidenced by the reduction of IKK $\beta$, p-IкB- $\alpha$ and nuclear p-p65 expression. We also measured the expression of IKK $\beta$, p-IкB- $\alpha$ and nuclear p-p65 in in spinal cord tissues of SCI mice using
A

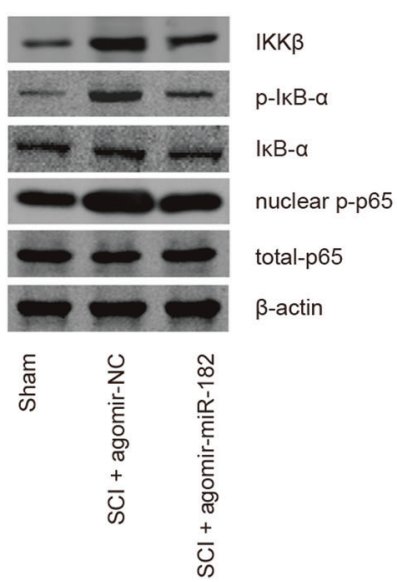

C

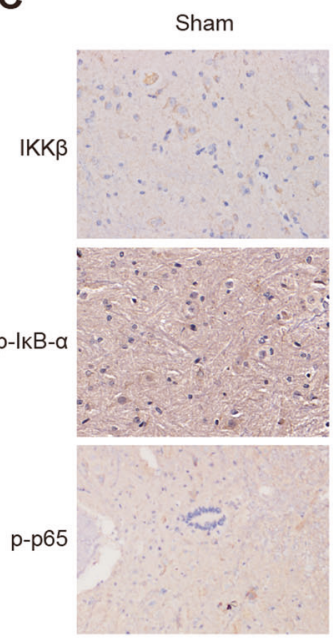

B

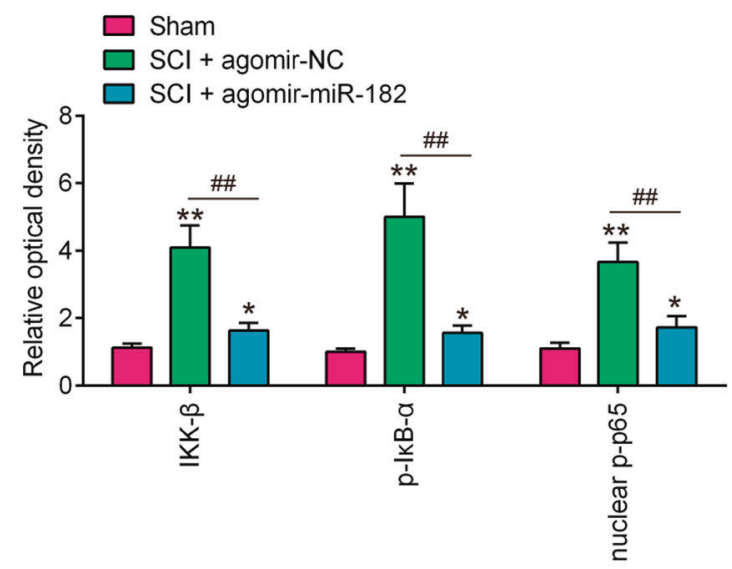

$\mathrm{SCl}+$ agomir-miR-182
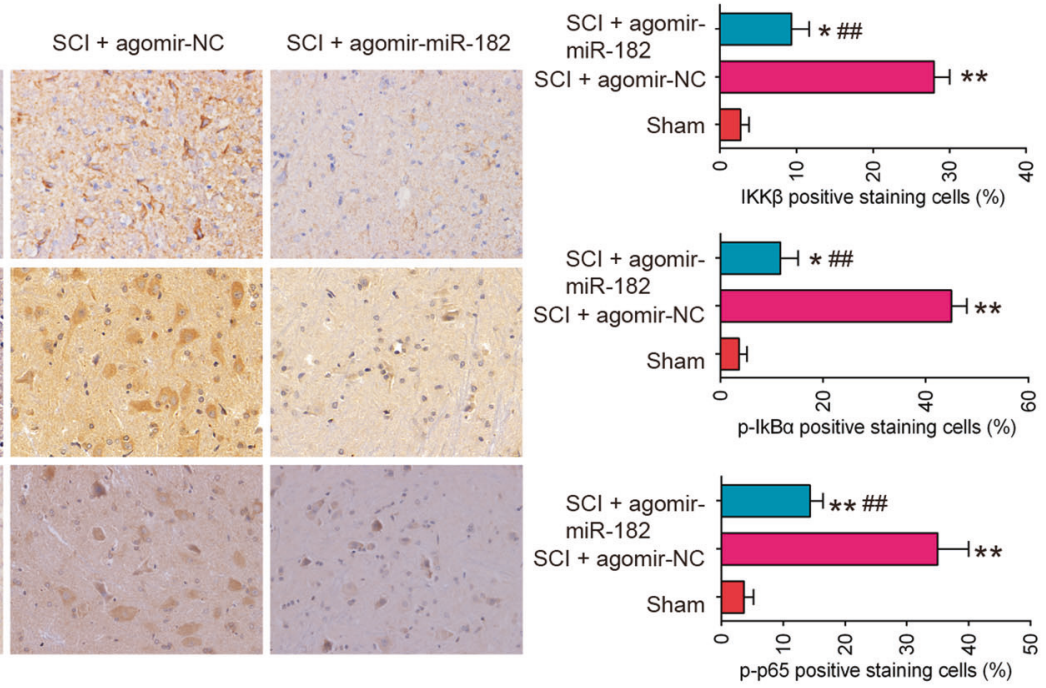

Fig. 7 miR-182 blocked the activation of the NF-кB pathway in vivo. The mice were subjected to SCI and treated intrathecally with agomir-miR-182/agomir-NC $(2 \mu \mathrm{l}, 20 \mu \mathrm{M})$. At 7 days post injury, the animals were sacrificed following pentobarbital sodium $(50 \mathrm{mg} / \mathrm{kg}$, i.p) anesthesia, and subsequently, the spinal cord tissues were harvested for further experiments. A The protein expression levels of IKK $\beta$, $p$-ІКB $\alpha$, I $\mathrm{B} \alpha$, nuclear-p-p65, and total p65 were detected by western blot analysis ( $n=6$ /group). B The bands were semi-quantitatively analyzed by using Image $\mathbf{J}$ software, normalized to $\beta$-actin density. $\mathbf{C}$ The expression of IKK $\beta$, p-IкB $\alpha$, and nuclear-p-p65 was detected by IHC. Data represent the mean $\pm \mathrm{SD}$ of three independent experiments. $* p<$ $0.05, * * p<0.01$ vs. Sham group; ${ }^{\# \#} p<0.01$ vs. SCI + agomir$\mathrm{NC}$ group. 
IHC. Compared with the sham group, the expression of IKK $\beta, \mathrm{p}-\mathrm{I} \kappa \mathrm{B}-\alpha$ and nuclear $\mathrm{p}$-p65 protein in the SCI group was significantly increased. After treatment with agomirmiR-182, the protein expression levels of IKK $\beta$, p-IкB- $\alpha$ and nuclear p-p65 were downregulated to varying degrees relative to the SCI group (Fig. 7C). These data suggest that miR-182 blocked NF- $\mathrm{NB}$ pathway activation by suppressing IKK $\beta$ expression in vivo.

\section{Discussion}

In the present study, miR-182 was significantly downregulated in spinal cord tissues of SCI mice. Overexpression of miR-182 improved the functional recovery of SCI mice through suppression of apoptosis and the inflammatory response. Using an LPS-induced BV-2 cell injury model, we found that overexpression of miR-182 protected BV-2 cells against LPS-induced apoptosis and the inflammatory response by suppressing the IKK $\beta / \mathrm{NF}-\kappa \mathrm{B}$ pathway. Notably, our data indicate that the overexpression of miR-182 exerted protective effects on the inflammatory response by blocking IKK $\beta / \mathrm{NF}-\kappa \mathrm{B}$ pathway activation in vivo and in vitro (Fig. 8). These findings suggest that miR-182 may be a potential target for the treatment of SCI.

A number of studies have demonstrated that miRNAs are aberrantly expressed in spinal cord tissues and associated with the SCI-induced inflammatory response and apoptosis $[16,45,46]$. For example, Zhou et al. found that miR-34a was downregulated in spinal cord tissues from SCI rat model, and miR-34a upregulation alleviated SCI through reducing apoptosis and inflammation via inhibition of high

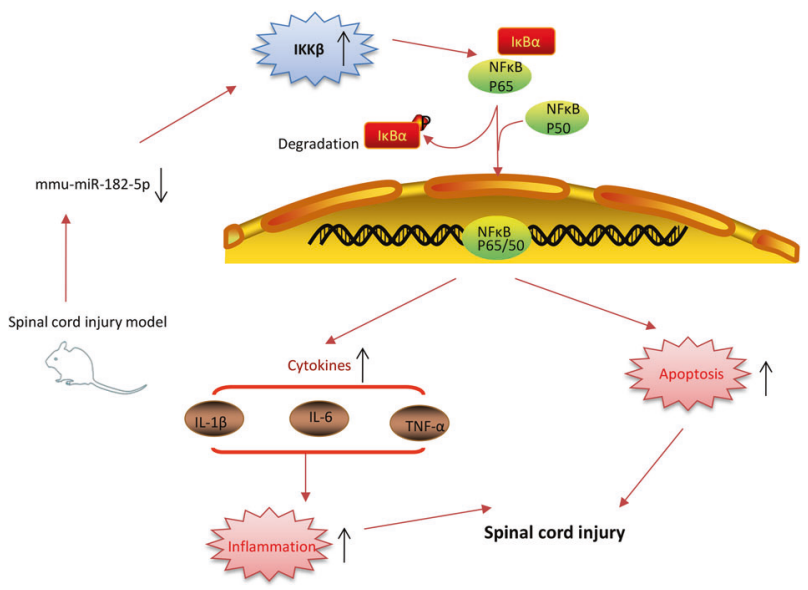

Fig. 8 A schematic illustration of the proposed model depicting miR-182 improves spinal cord injury in mice by modulating apoptosis and the inflammatory response via IKK $\beta / \mathrm{NF}-\kappa \mathrm{B}$. Schematic diagrams showing that miR-182 was downregulated in SCI mice, and induced the expression of its target IKK $\beta$, thus promoting the activation of the NF- $\mathrm{KB}$ pathway, resulting in an inflammatory response and apoptosis, leading to secondary damage. mobility group box-1 expression in TLR4 signaling [47]. Chen et al. showed that miR-92b-3p promoted functional recovery of SCI mice through the PTEN/AKT pathway [48]. Dai et al. found that miR-210 was significantly reduced in SCI mice, and miR-210 overexpression alleviated the progression of SCI by inhibiting inflammation [49]. In the present study, we analyzed GSE19890 from the GEO database to determine the expression pattern of miRNAs in spinal cord tissues of SCI mice. According to the GEO database, we found that several miRNAs including miR-182, miR-21, miR-223 miR-124 and miR-126, were abnormal in the spinal cord tissues, which are consistent with previous reports [20, 24, 34, 35], indicating the reliability of this microarray. Among these miRNAs, we found miR-182 was the most downregulated miRNA in spinal cord tissues from SCI mice, suggesting the involvement of miR-182 in SCI.

The function of miR-182 in inflammation has been extensively investigated. For example, Jiang et al. found that miR-182 alleviated liver injury through inhibiting TLR4mediated inflammatory reaction in a hepatic ischemiareperfusion (I/R) injury rat model [39]. Wang et al. has demonstrated that miR-182 improved the cerebral injury via suppressing the TLR4-mediated inflammation [36]. Notably, a recent study showed the neuroprotective effect of miR-182 in mice following SCI by suppressing the neurons apoptosis [41]. These findings prompted us to investigate the role of miR-182 in inflammatory responses in SCI. Here we conducted a miR-182-based strategy to treat SCI using the agomir-miR-182. We found that agomir-miR-182 injection could improve the functional recovery, reduce lesion size and spinal cord water edema after SCI. Given the destructive role of the inflammatory response and apoptosis in SCI progression, we also inferred that miR-182 might affect the neuronal inflammatory response and apoptosis in SCI. As expected, forced expression of miR-182 effectively suppressed the inflammatory response and apoptosis in SCI mice. Consistent with the in vivo results, it was also observed that miR-182 overexpression exhibited its protective effects against the LPS-induced inflammatory response and apoptosis using LPS-induced BV-2 cell injury model. The data suggest that miR-182 protects the spinal cord from secondary damage and facilitate recovery after SCI in mice.

IKK $\beta$, one component of the IKK complex, has received attention in SCI for its essential contributions to $\mathrm{I} \kappa \mathrm{B}$ phosphorylation and NF- $\kappa \mathrm{B}$ activation [7]. For example, Kang et al. found that IKK $\beta$-mediated neutrophil activation in the injured spinal cord exacerbated inflammation and neuronal damage and impeded functional recovery after SCI [50]. Several studies have shown that the activation of IKK $\beta$ in SCI is finely regulated by miRNAs. Deng et al. reported that miR-136-5p ameliorated the SCI through repressing the inflammatory cell infiltration by directly targeting IKK $\beta$ 
[51]. Zhou et al. demonstrated that miR-199b attenuated acute SCI through regulation of the IKK $\beta / \mathrm{NF}-\mathrm{\kappa B}$ signaling pathway [29]. However, whether IKK $\beta$ is involved in the protection of miR-182 against SCI remains unclear. In our study, IKK $\beta$ was confirmed as a direct target of miR-182 in SCI cell culture model. In addition, the protective effects of miR-182 against LPS-induced apoptosis and inflammatory response were abrogated by the overexpression of IKK $\beta$, suggesting that miR-182 protected against LPS-induced BV-2 cell injury via suppressing the expression of IKK $\beta$.

It is well known that the IKK $\beta$ is an inducer of the NF$\kappa \mathrm{B}$ pathway through promotion of phosphorylation of the I $\mathrm{B}$ protein $[10,52,53]$. Activation of the NF- $\mathrm{KB}$ signaling pathway has been closely associated with the inflammatory response after SCI [54]. Previous studies have reported that miRNAs play key roles in inflammatory response through the suppression of the NF- $\mathrm{kB}$ pathway. Yang et al. showed that miR-146a could suppress inflammatory response in SCI through inhibition of NF- $\mathrm{KB}$ pathway [30]. Given IKK $\beta$ is directly targeted by miR-182, we hypothesized that miR182 suppress the inflammatory responses by the IKK $\beta / \mathrm{NF}$ $\kappa B$ pathway. In this study, it was observed that the miR-182 overexpression significantly inhibited the activation of NF$\kappa \mathrm{B}$ in vitro and in vivo, which can be used to partially explain the reduction of inflammatory cytokines. Furthermore, overexpression of IKK $\beta$ reactivated the NF- $\mathrm{KB}$ pathway blocked by miR-182 in SCI cell culture model. These results suggest that miR-182 exerts its protective effects against SCI-induced inflammatory response by inhibiting the IKK $\beta / \mathrm{NF}-\mathrm{\kappa B}$ signaling pathway.

Many studies have reported the protective effects of miRNAs from different cellular source types including neuron and astrocytes, during the progression of SCI. For example, Zhang et al. found that miR-21 was upregulated in neurons after SCI, and overexpression of miR-21 reduced neuronal apoptosis by targeting PDCD [55]. Lv et al. showed that overexpression of miR-448 improved spinal motor neuron regeneration by regulating the PI3K/AKT/ Bcl-2 axis [56]. Yuan et al. reported that miR-124 inhibited primary spinal neuronal apoptosis by suppressing the GCH1 expression [57]. In the central nervous system, astrocytes are the most abundant and widely distributed glial cells and it has been considered as the ideal therapeutic target cells for SCI [58, 59]. For example, Bhalala et al. found miR-21 was highly expressed in astrocytes in injured spinal cord and inhibition of miR-21 attenuated astrocytic hypertrophy and glial scar progression following SCI [60]. In addition, in microglia, miR-223-5p was upregulated in M1 microglia, and miR-223-5p inhibition suppressed the inflammatory response and reduced glia reaction and neuron apoptosis in SCI 34. In this study, we observed that the injury site of SCI mice with abundant glial cells proliferation and satellitosis, suggesting miR-182 may exert its protective effect through regulating glial cell biological functions. Thus, we chose a microglia cell line (BV2) for subsequent experiments. Further investigation showed that overexpression of miR182 suppressed the LPS-induced inflammatory response and apoptosis in BV-2 cells, which is consistent the in vivo results. Therefore, we concluded that the cellular miR-182 from glial may play an important role in protection against SCI. However, whether other cellular miR-182 also participate in protection against SCI need further study.

In conclusion, we demonstrated that miR-182 improved secondary damage and facilitate recovery by inhibiting the inflammatory responses and apoptosis via inactivation of the IKK $\beta / \mathrm{NF}-\kappa \mathrm{B}$ pathway (Fig. 8). Our findings suggest that miR-182 may be a therapeutic target of SCI.

\section{Data availability}

The data used to support the findings of this study are included within the article.

Author contributions $\mathrm{MF}$ and $\mathrm{ZL}$ performed all the experimental work. YC and CJ participated in data analysis. HL and ZC conceived and participated in the design of the study. The manuscript was written by HL and ZC. All authors read and approved the final manuscript.

Funding The study was supported by the National Natural Science Foundation of China (81301047).

\section{Compliance with ethical standards}

Conflict of interest The authors declare no competing interests.

Ethics approval All experimental procedures were approved by the Animal Ethics Committee of Zhongshan Hospital, Fudan University.

Publisher's note Springer Nature remains neutral with regard to jurisdictional claims in published maps and institutional affiliations.

Open Access This article is licensed under a Creative Commons Attribution 4.0 International License, which permits use, sharing, adaptation, distribution and reproduction in any medium or format, as long as you give appropriate credit to the original author(s) and the source, provide a link to the Creative Commons license, and indicate if changes were made. The images or other third party material in this article are included in the article's Creative Commons license, unless indicated otherwise in a credit line to the material. If material is not included in the article's Creative Commons license and your intended use is not permitted by statutory regulation or exceeds the permitted use, you will need to obtain permission directly from the copyright holder. To view a copy of this license, visit http://creativecommons. org/licenses/by/4.0/.

\section{References}

1. Bowes AL, Yip PK. Modulating inflammatory cell responses to spinal cord injury: all in good time. $J$ Neurotrauma. 2014;31:1753-66. 
2. Hu W, Wang H, Liu Z, Liu Y, Wang R, Luo X, et al. Neuroprotective effects of lycopene in spinal cord injury in rats via antioxidative and anti-apoptotic pathway. Neurosci Lett. 2017;642:107-12.

3. Goldshmit Y, Kanner S, Zacs M, Frisca F, Pinto AR, Currie PD, et al. Rapamycin increases neuronal survival, reduces inflammation and astrocyte proliferation after spinal cord injury. Mol Cell Neurosci. 2015;68:82-91.

4. Blight AR. Delayed demyelination and macrophage invasion: a candidate for secondary cell damage in spinal cord injury. Cent Nerv Syst Trauma. 1985;2:299-315.

5. Orr MB, Gensel JC. Spinal cord injury scarring and inflammation: therapies targeting glial and inflammatory responses. Neurotherapeutics. 2018;15:541-53.

6. Qin S, Yang C, Huang W, Du S, Mai H, Xiao J, et al. Sulforaphane attenuates microglia-mediated neuronal necroptosis through down-regulation of MAPK/NF-kappaB signaling pathways in LPS-activated BV-2 microglia. Pharmacol Res. 2018;133:218-35.

7. Zhou HJ, Wang LQ, Wang DB, Yu JB, Zhu Y, Xu QS, et al. Long noncoding RNA MALAT1 contributes to inflammatory response of microglia following spinal cord injury via the modulation of a miR-199b/IKKbeta/NF-kappaB signaling pathway. Am J Physiol Cell Physiol. 2018;315:C52-61.

8. Ning SL, Zhu H, Shao J, Liu YC, Lan J, Miao J. MiR-21 inhibitor improves locomotor function recovery by inhibiting IL-6R/JAKSTAT pathway-mediated inflammation after spinal cord injury in model of rat. Eur Rev Med Pharmacol Sci. 2019;23:433-40.

9. Xia Y, Shen S, Verma IM. NF-kappaB, an active player in human cancers. Cancer Immunol Res. 2014;2:823-30.

10. Karin M, Ben-Neriah Y. Phosphorylation meets ubiquitination: the control of NF-[kappa]B activity. Annu Rev Immunol. 2000;18:621-63.

11. Bulek K, Liu C, Swaidani S, Wang L, Page RC, Gulen MF, et al. The inducible kinase IKKi is required for IL-17-dependent signaling associated with neutrophilia and pulmonary inflammation. Nat Immunol. 2011;12:844-52.

12. Awane M, Andres PG, Li DJ, Reinecker HC. NF-kappa B-inducing kinase is a common mediator of IL-17-, TNF-alpha-, and IL1 beta-induced chemokine promoter activation in intestinal epithelial cells. J Immunol. 1999;162:5337-44.

13. Croce CM. Causes and consequences of microRNA dysregulation in cancer. Nat Rev Genet. 2009;10:704-14.

14. Bartel DP. MicroRNAs: target recognition and regulatory functions. Cell. 2009;136:215-33.

15. Wu WD, Wang LH, Wei NX, Kong DH, Shao G, Zhang SR, et al. MicroRNA-15a inhibits inflammatory response and apoptosis after spinal cord injury via targeting STAT3. Eur Rev Med Pharmacol Sci. 2019;23:9189-98.

16. Feng JS, Sun JD, Wang XD, Fu CH, Gan LL, Ma R. MicroRNA204-5p targets SOX11 to regulate the inflammatory response in spinal cord injury. Eur Rev Med Pharmacol Sci. 2019;23:4089-96.

17. Liu NK, Wang XF, Lu QB, Xu XM. Altered microRNA expression following traumatic spinal cord injury. Exp Neurol. 2009;219:424-9.

18. Liu G, Keeler BE, Zhukareva V, Houle JD. Cycling exercise affects the expression of apoptosis-associated microRNAs after spinal cord injury in rats. Exp Neurol. 2010;226:200-6.

19. Wang B, Shen PF, Qu YX, Zheng C, Xu JD, Xie ZK, et al. miR940 promotes spinal cord injury recovery by inhibiting TLR4/NFkappaB pathway-mediated inflammation. Eur Rev Med Pharmacol Sci. 2019;23:3190-7.

20. Xu Z, Zhang K, Wang Q, Zheng Y. MicroRNA124 improves functional recovery and suppresses Baxdependent apoptosis in rats following spinal cord injury. Mol Med Rep. 2019;19: 2551-60.
21. Zhu H, Xie R, Liu X, Shou J, Gu W, Gu S, et al. MicroRNA-494 improves functional recovery and inhibits apoptosis by modulating PTEN/AKT/mTOR pathway in rats after spinal cord injury. Biomed Pharmacother. 2017;92:879-87.

22. Cai W, Zhao Q, Shao J, Zhang J, Li L, Ren X, et al. MicroRNA182 Alleviates Neuropathic Pain by Regulating Nav1.7 Following Spared Nerve Injury in Rats. Sci Rep. 2018;8:16750.

23. Basso DM, Beattie MS, Bresnahan JC. A sensitive and reliable locomotor rating scale for open field testing in rats. J Neurotrauma. 1995;12:1-21.

24. Hu JZ, Huang JH, Zeng L, Wang G, Cao M, Lu HB. Antiapoptotic effect of microRNA-21 after contusion spinal cord injury in rats. J Neurotrauma. 2013;30:1349-60.

25. Li JM, Ge CX, Xu MX, Wang W, Yu R, Fan CY, et al. Betaine recovers hypothalamic neural injury by inhibiting astrogliosis and inflammation in fructose-fed rats. Mol Nutr Food Res. 2015;59:189-202.

26. Barrett T, Wilhite SE, Ledoux P, Evangelista C, Kim IF, Tomashevsky $\mathrm{M}$, et al. NCBI GEO: archive for functional genomics data sets-update. Nucleic Acids Res. 2013;41:D991-5.

27. Deng W, Wang Y, Liu Z, Cheng H, Xue Y. HemI: a toolkit for illustrating heatmaps. PLoS One. 2014;9:e111988.

28. Livak KJ, Schmittgen TD. Analysis of relative gene expression data using real-time quantitative PCR and the 2(-Delta Delta $\mathrm{C}(\mathrm{T})$ ) Method. Methods. 2001;25:402-8.

29. Zhou HJ, Wang LQ, Xu QS, Fan ZX, Zhu Y, Jiang H, et al. Downregulation of miR-199b promotes the acute spinal cord injury through IKKbeta-NF-kappaB signaling pathway activating microglial cells. Exp Cell Res. 2016;349:60-7.

30. Tan Y, Yu L, Zhang C, Chen K, Lu J, Tan L. miRNA-146a attenuates inflammation in an in vitro spinal cord injury model via inhibition of TLR4 signaling. Exp Ther Med. 2018;16:3703-9.

31. Ding Y, Wang L, Zhao Q, Wu Z, Kong L. MicroRNA93 inhibits chondrocyte apoptosis and inflammation in osteoarthritis by targeting the TLR4/NFkappaB signaling pathway. Int J Mol Med. 2019;43:779-90.

32. Yu X, Zhang S, Zhao D, Zhang X, Xia C, Wang T, et al. SIRT1 inhibits apoptosis in in vivo and in vitro models of spinal cord injury via microRNA-494. Int J Mol Med. 2019;43:1758-68.

33. Ghavami S, Hashemi M, Ande SR, Yeganeh B, Xiao W, Eshraghi $\mathrm{M}$, et al. Apoptosis and cancer: mutations within caspase genes. J Med Genet. 2009;46:497-510.

34. Guan YZ, Sun C, Wang HL, Xia XL, Lu FZ, Song J, et al. MiR223-5p inhibitor suppresses microglia inflammation and promotes Nrg-1 in rats of spinal cord injury. Eur Rev Med Pharmacol Sci. 2019;23:9746-53.

35. Hu J, Zeng L, Huang J, Wang G, Lu H. miR-126 promotes angiogenesis and attenuates inflammation after contusion spinal cord injury in rats. Brain Res. 2015;1608:191-202.

36. Wang J, Xu Z, Chen X, Li Y, Chen C, Wang C, et al. MicroRNA$182-5 p$ attenuates cerebral ischemia-reperfusion injury by targeting Toll-like receptor 4. Biochem Biophys Res Commun. 2018;505:677-84.

37. Zhao J, Li X, Hu J, Chen F, Qiao S, Sun X, et al. Mesenchymal stromal cell-derived exosomes attenuate myocardial ischaemiareperfusion injury through miR-182-regulated macrophage polarization. Cardiovasc Res. 2019;115:1205-16.

38. Qin SB, Peng DY, Lu JM, Ke ZP. MiR-182-5p inhibited oxidative stress and apoptosis triggered by oxidized low-density lipoprotein via targeting toll-like receptor 4. J Cell Physiol. 2018;233:6630-7.

39. Jiang W, Liu G, Tang W. MicroRNA-182-5p ameliorates liver ischemia-reperfusion injury by suppressing toll-like receptor 4 . Transplant Proc. 2016;48:2809-14.

40. Blaya D, Coll M, Rodrigo-Torres D, Vila-Casadesus M, Altamirano $\mathrm{J}$, Llopis $\mathrm{M}$, et al. Integrative microRNA profiling in 
alcoholic hepatitis reveals a role for microRNA-182 in liver injury and inflammation. Gut. 2016;65:1535-45.

41. Ling W, Xu X, Liu J. A causal relationship between the neurotherapeutic effects of miR182/7a and decreased expression of PRDM5. Biochem Biophys Res Commun. 2017;490:1-7.

42. Hu F, Min J, Cao X, Liu L, Ge Z, Hu J, et al. MiR-363-3p inhibits the epithelial-to-mesenchymal transition and suppresses metastasis in colorectal cancer by targeting Sox4. Biochem Biophys Res Commun. 2016;474:35-42.

43. Monga S, Nagler R, Amara R, Weizman A, Gavish M. Inhibitory effects of the two novel TSPO ligands 2-Cl-MGV-1 and MGV-1 on LPS-induced microglial activation. Cells. 2019;8:486.

44. Huang Y, Zhu N, Chen T, Chen W, Kong J, Zheng W, et al. Triptolide suppressed the microglia activation to improve spinal cord injury through miR-96/IKKbeta/NF-kappaB pathway. Spine. 2019;44:E707-14.

45. Sun Y, Liu B, Zheng X, Wang D. Notoginsenoside R1 alleviates lipopolysaccharide-triggered $\mathrm{PC}-12$ inflammatory damage via elevating microRNA-132. Artif Cells Nanomed Biotechnol. 2019;47:1808-14.

46. Wang Y, Yuan Y, Gao Y, Li X, Tian F, Liu F, et al. MicroRNA31 regulating apoptosis by mediating the phosphatidylinositol-3 kinase/protein kinase B signaling pathway in treatment of spinal cord injury. Brain Dev. 2019;41:649-61.

47. Zhou J, Shuang O, Li J, Cai Z, Wu C, Wang W. miR-34a alleviates spinal cord injury via TLR4 signaling by inhibiting HMGB1. Exp Ther Med. 2019;17:1912-8.

48. Chen Z, Li Z, Jiang C, Jiang X, Zhang J. MiR-92b-3p promotes neurite growth and functional recovery via the PTEN/AKT pathway in acute spinal cord injury. J Cell Physiol. 2019;234:23043-52.

49. Dai J, Yu GY, Sun HL, Zhu GT, Han GD, Jiang HT, et al. MicroRNA-210 promotes spinal cord injury recovery by inhibiting inflammation via the JAK-STAT pathway. Eur Rev Med Pharmacol Sci. 2018;22:6609-15.

50. Kang J, Jiang MH, Min HJ, Jo EK, Lee S, Karin M, et al. IKKbeta-mediated myeloid cell activation exacerbates inflammation and inhibits recovery after spinal cord injury. Eur J Immunol. 2011;41:1266-77.

51. Deng G, Gao Y, Cen Z, He J, Cao B, Zeng G, et al. miR-136-5p regulates the inflammatory response by targeting the IKKbeta/NFkappaB/A20 pathway after spinal cord injury. Cell Physiol Biochem. 2018;50:512-24.

52. Li Q, Van Antwerp D, Mercurio F, Lee KF, Verma IM. Severe liver degeneration in mice lacking the IkappaB kinase 2 gene. Science. 1999;284:321-5.

53. Li ZW, Chu W, Hu Y, Delhase M, Deerinck T, Ellisman M, et al. The IKKbeta subunit of IkappaB kinase (IKK) is essential for nuclear factor kappaB activation and prevention of apoptosis. $\mathbf{J}$ Exp Med. 1999;189:1839-45.

54. Bank M, Stein A, Sison C, Glazer A, Jassal N, McCarthy D, et al. Elevated circulating levels of the pro-inflammatory cytokine macrophage migration inhibitory factor in individuals with acute spinal cord injury. Arch Phys Med Rehabil. 2015;96: 633-44.

55. Zhang T, Ni S, Luo Z, Lang Y, Hu J, Lu H. The protective effect of microRNA-21 in neurons after spinal cord injury. Spinal Cord. 2019;57:141-9.

56. Lv CL, Zhang T, Yan TZ, Yi GK, Gao K. MicroRNA-448 inhibits the regeneration of spinal cord injury through PI3K/AKT/Bcl-2 axis. Eur Rev Med Pharmacol Sci. 2019;23:2719-26.

57. Yuan S, Wang YX, Gong PH, Meng CY. MiR-124 inhibits spinal neuronal apoptosis through binding to GCH1. Eur Rev Med Pharmacol Sci. 2019;23:4564-74.

58. Huang X, Gu YK, Cheng XY, Su ZD. [Astrocytes as therapeutic targets after spinal cord injury]. Sheng Li Xue Bao. 2017;69: 794-804.

59. Jorge A, Taylor T, Agarwal N, Hamilton DK. Current agents and related therapeutic targets for inflammation after acute traumatic spinal cord injury. World Neurosurg. 2019;132:138-47.

60. Bhalala OG, Pan L, Sahni V, McGuire TL, Gruner K, Tourtellotte WG, et al. microRNA-21 regulates astrocytic response following spinal cord injury. J Neurosci. 2012;32:17935-47. 